\title{
VARIABILIDADE ESPACIAL DA FAUNA DO SOLO CULTIVADO COM SOJA SOB SEMEADURA DIRETA (MARANHÃO, BRASIL)
}

\author{
Iara Regina Ferreira do Carmo ${ }^{1}$, Glécio Machado Siqueira ${ }^{1}$ \\ ${ }^{1}$ Universidade Federal do Maranhão
}

DOI: 10.47094/ICONNECA.2021/10

Introdução: O solo é um sistema natural que abriga vários organismos vivos, sendo desta maneira um sistema dinâmico. Objetivo: Avaliar a diversidade da fauna edáfica sob sistema de semeadura direta com soja no Estado do Maranhão. Metodologia: A área estudada compreende cerca de 44,75 hectares de plantio de soja (Glicine $\max$ L.). Foram feitas coletas de solo em duas profundidades (0.0-0.2m e $0.2-0.4 \mathrm{~m})$ em 70 pontos. Foram alocadas 70 armadilhas do tipo pitfall ao longo da área, e cada armadilha permaneceu por um período de 7 dias. Coletou-se 1.009 espécimes distribuídos em 16 grupos taxonômicos. Resultados: Os grupos com maiores abundâncias foram Larva de Coleoptera (318 espécimes), Coleoptera (299 espécimes), Diptera (121 espécimes), Formicidae (109 espécimes) e Acari (102 espécimes). A diversidade de Shannon-Wiener e equitabilidade de Pielou foi de H'=2.482 e U'=0.620. A maior abundância de Coleoptera, Formicidae e Acari podem indicar o potencial desses grupos como bioindicadores de qualidade ambiental. O modelo geoestatístico esférico foi o que mais ajustou-se aos índices de diversidade, com variação de efeito pepita de $\left(\mathrm{C}_{0}\right)$ de 0.036 para diversidade de Simpson á 24 para diversidade de Menhinick. Para os valores de variância estrutural $\left(\mathrm{C}_{1}\right)$ a variação foi 0.04 para a dominância de Simpson á 35 para a diversidade Menhinick. O grau de dependência espacial para os índices foi moderado, com alcance (m) variando de 150 a 235 (m). Considerações Finais: Os mapas de variabilidade apresentam padrões semelhantes para a diversidade de Shannon e Simpson, uma vez que são considerados parâmetros iguais. A equitabilidade apresentou maiores valores na parte superior e inferior a direita, esclarecendo que a distribuição de grupos não foi homogênea na área. O manejo adotado na área com semeadura direta, favoreceu a presença de fauna edáfica, principalmente Acari, Coleoptera, larva de coleoptera e Fomicidae.

PALAVRAS-CHAVE: Fauna Edáfica. Bioindicadores. Agricultura de Precisão.

ÁREA TEMÁTICA: Tecnologia e produção. 